\title{
JOURNAL OF THE ROYAL SOCIETY OF MEDICINE
}

\author{
October 2007 Volume 100 Number 10 ISSN 0141-0768
}

\section{A NICE debate likely to turn nasty}

Two themes dominate this issue of the JRSM. First we have a collection of articles on the National Institute for Health and Clinical Excellence, which was created around the time of another organization called the Commission for Health Improvement. Together they were sometimes known as 'NICE and nasty'. While the Commission for Health Improvement is rediscovering itself as the Healthcare Commission, NICE has managed to cling on to its acronym and its leadership.

Without doubt NICE is a much stronger and much more influential organization than it once was. Guidelines that were once automatically redirected to the nearest wastepaper basket now have to be scanned for the NICE logo, a brand that has to be taken seriously. NICE has now published nearly 50 clinical guidelines and over 30 more are in production. In addition, NICE has ventured into public health, with five sets of guidance published and 15 more in development. This constitutes probably the largest clinical guideline programme in the world.

But is it effective? NICE can regulate the introduction of new technologies into the NHS but it cannot end variable performance. Guidelines have a miserable record in changing clinical practice, even though Jayne Chidgey and colleagues from NICE suggest that they help ensure that patients derive full benefits from clinical research (JRSM 2007;100:448-52). The challenge, however, remains one of implementation and the authors present a mixed picture of success. The central problem for NICE is that too many clinicians view its rationing role with displeasure, and each decision and guidance brings its own enemies.

Iain Chalmers, a member of the NICE research and development advisory committee, observes that there is plenty of room for improvement in the difficult area of changing professional practice (JRSM 2007;100:440-41). He also believes that NICE is wasting an important opportunity, when uncertainty exists, to use drugs only in the context of further research. Indeed, the recent legal challenge mounted by manufacturers and the Alzheimer's Society against NICE's decision on anti-cholinergic drugs might have been avoided if the drug had been approved for research only. Chalmers urges NICE to use this option more frequently and Kalipso Chalkidou and colleagues analyze this issue further, concluding that these policy issues need to be 'driven by those of us who use the NHS' (JRSM 2007;100:453-60).

Susham Gupta and James Warner are less polite (JRSM 2007;100:442-43). For them - and perhaps they speak for many of their clinical colleagues - the government and NICE must address their failings 'before expecting all involved to accept their pronouncements without questioning.' But finite resources make rationing inevitable and the challenge for a health service, as John Muir Gray explains in his new book, is to deliver maximum value (JRSM 2007;100:480). It is hard to argue with iron rules of economics but the problem for NICE, as with many national organizations, is that clinicians feel increasingly isolated from the decision-making process and increasingly resentful of the inflexibility of high-level commandments.

A future role of NICE might be to pontificate on the value of spinal manipulation - the second dominant theme in this issue-although I doubt it would settle the row played out in the letters pages this month (JRSM 2007;100:444-47). But NICE, like spinal manipulation, has survived longer than many critics expected. It is embedded in the NHS not shooting from the sidelines, and its concept has been favourably reviewed by the World Health Organization and exported to other countries. NICE is here to stay, but the debates about its effectiveness are likely to get nastier.

\section{Kamran Abbasi}

Editor, JRSM

[Kamran.abbasi@rsm.ac.uk]

\section{Peer reviewers}

- Deborah Bowman, University of London, UK

- Elizabeth Chapman, West Middlesex University Hospital, UK

- Alison Chisholm, Picker Institute Europe, Oxford, UK

- Arthur Hollman, Pett, UK

- Roger Jones, Kings College London, UK

- Janet McComb, Freeman Hospital, Newcastle, UK

- Jaykar Panchmatia, National Hospital for Neurology and Neurosurgery, London, UK
- Peter Perkins, Southbourne Surgery, Bournemouth, UK

- Laura Price, Hammersmith Hospital, London, UK

- Roisin Pill, University of Wales, UK

- John Sharpley, Royal Naval Psychiatry, Portsmouth, UK

- Karol Sikora, CancerPartnersUK, London

- Steve Wilkinson, University of East Anglia, UK 